\title{
Nanocasting Process to Pore-Expanded Ordered Mesoporous Carbons with 2D Hexagonal Mesostructure
}

\author{
Chongwen Jiang, Keyuan Zhou, and Xin Zhong \\ College of Chemistry and Chemical Engineering, Central South University, Changsha 410083, China \\ Correspondence should be addressed to Keyuan Zhou; keyuanzhou@163.com
}

Received 3 November 2013; Accepted 16 January 2014; Published 23 February 2014

Academic Editor: Alfons Baiker

Copyright (C) 2014 Chongwen Jiang et al. This is an open access article distributed under the Creative Commons Attribution License, which permits unrestricted use, distribution, and reproduction in any medium, provided the original work is properly cited.

Pore-expanded ordered mesoporous carbons with 2D hexagonal mesostructure were synthesized by a simple nanocasting process. We adopted sucrose as carbon precursors, mesoporous silica materials SBA- 15 as the hard templates, and hexane as micelle swelling agents. The pore size distribution of OMCs was narrow and centered at $5.4 \mathrm{~nm}$, which is larger than the upper limit of pore diameters typically reported for CMK-3. The BET surface area and mesopore volume of PE-CMK-3 can reach to $1213.47 \mathrm{~m}^{2} / \mathrm{g}$ and $1.56 \mathrm{~cm} / \mathrm{g}$, respectively, indicating that choosing large pore size materials as template is good for preparation of high performance of OMCs.

\section{Introduction}

Since first report in 1999 [1], ordered mesoporous carbons (OMCs) have attracted considerable attention because of their special structural properties, such as large surface area, large pore volume, and narrow pore size distribution, and have been widely used in catalysis, adsorption, optics devices, electrodes, and preparation of new materials [2-6]. One way to render such nanoscale carbon materials is the generation of mesoporosity based on the so-called softand hard-templating methods. The hard-templating method has been proven to be versatile for the synthesis of OMC materials $[7,8]$, which utilizes mesoporous silica as the hard template to fill with a carbon precursor, followed by high temperature carbonization with subsequent removal of the silica framework by hydrofluoric acid or sodium hydroxide, and easy to obtain mesoporous carbons with a controlled structure and shape on the nanometer scale.

The soft-template procedures directly use surfactant as the templates for the generation of porous carbon structures without extra step of generating silica templating structures. Compared with the hard-templating method, the soft-template procedure seems very convenient. However, it requires well-selected conditions for the carbon precursors
[9]. During the high temperature carbonization process, the framework shrinkage is very serious, and the pore size is also not easy to control.

The pore size of OMCs seriously hindered its application, and the typically reported pore size of OMCs is less than $5 \mathrm{~nm}$, and the unit-cell parameter is below $10 \mathrm{~nm}$. The shape and properties of OMC mainly depend on the template structure, and plenty of work has been done in expanding the pore size of OMCs. Lee et al. [10] synthesized OMCs with tunable pores by using boric acid as pore expanding agent, and the pore size can be tuned in the range of 3-10 nm, but the pore structure is gradually disordered. The pore size of OMC can be efficiently tuned by the elaborate design of the template structure. Li et al. [11] have done much similar research work. Many researchers have reported that many kinds of organic cosolvents such as 1,3,5-trimethylbenzene (TMB), alkanes, and amines are suitable to expand the volume of the micelle. Kruk synthesized pore-expanded SBA15 by using $n$-hexane as micelle expander, and the diameter of cylindrical pores in $2 \mathrm{D}$ hexagonal structures could be increased from $9 \mathrm{~nm}$ (typical of SBA-15) to $12-15 \mathrm{~nm}$ [12]. The pore size of SBA- 15 can be expanded up to $26 \mathrm{~nm}$ by using 1,3,5-triisopropylbenzene (TIPB) as swelling agent [13]. In order to better tailor the pore size, we choose hexane 


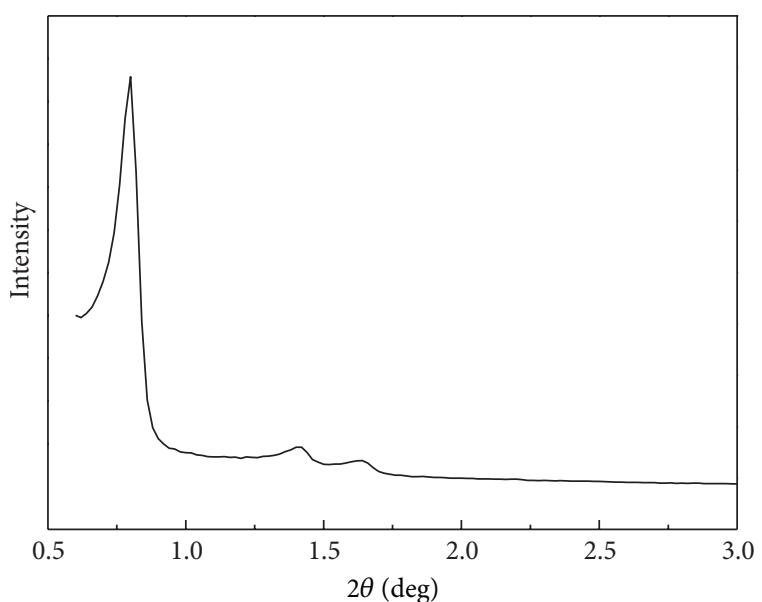

(a)

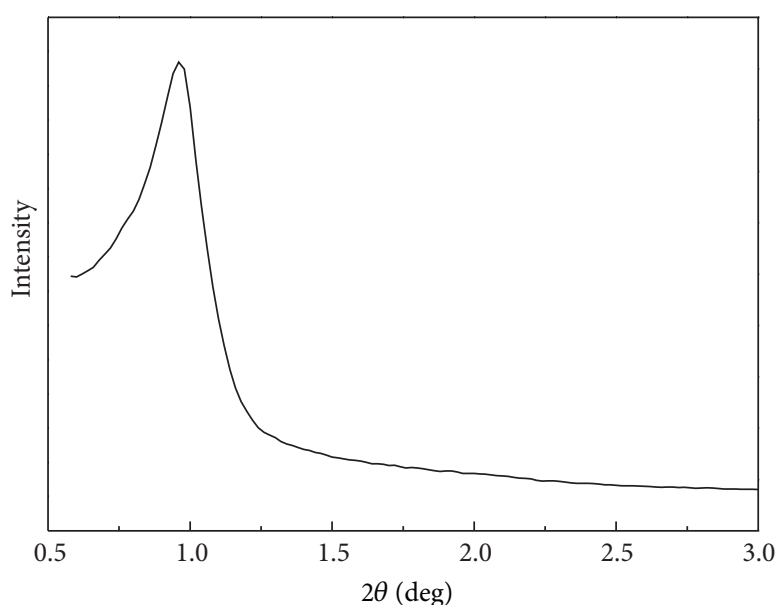

(b)

FIgure 1: Powder XRD patterns of (a) SBA-15 and (b) CMK-3.

as swelling agent and synthesized pore-expanded SBA-15 and then obtained pore-expanded CMK-3 through a simple nanocasting process.

\section{Experimental}

2.1. Preparation of Pore-Expanded SBA-15. Pore-expanded 2D hexagonally ordered mesoporous silica SBA-15 hard templates were prepared as previously reported with some modification [14]. The molar ratio of synthesis compositions was in the range of P123:TEOS: $\mathrm{C}_{6} \mathrm{H}_{14}: \mathrm{HCl}: \mathrm{H}_{2} \mathrm{O}=$ 1:58.5:240:352.9:11765.3 g triblock copolymer P123 (Aldrich, $\mathrm{M}_{\mathrm{av}}=5800$ ) which was dissolved in $99 \mathrm{~g}$ of distilled water and $15 \mathrm{~mL}$ hydrochloric acid (37\%) under stirring at room temperature. $16 \mathrm{~mL}$ of hexane was added and stirred at $15^{\circ} \mathrm{C}$ for $1 \mathrm{~h}$, followed by the slow addition of $6.3 \mathrm{~g}$ of TEOS with vigorous stirring. The resultant solution was kept at $15^{\circ} \mathrm{C}$ for $20 \mathrm{~h}$ under stirring. Then, the reaction mixture was aged at $100^{\circ} \mathrm{C}$ for $24 \mathrm{~h}$ under static conditions. The products were collected by filtration, dried at $60^{\circ} \mathrm{C}$, and calcined at $813 \mathrm{~K}$ for $5 \mathrm{~h}$ to remove the templates. The highly ordered SBA-15 silica with large cylindrical pores was thus obtained. The calcined sample is denoted as PE-SBA-15 and without adding hexane is denoted as SBA-15.

2.2. Preparation of OMCs. The procedure for the synthesis of OMC materials is the same as the nanocasting method described elsewhere [7]. $1 \mathrm{~g}$ of PE-SBA-15 or SBA-15 was added to a solution obtained by dissolving $1.3 \mathrm{~g}$ of sucrose and $0.15 \mathrm{~g}$ of $\mathrm{H}_{2} \mathrm{SO}_{4}$ in $5 \mathrm{~g}$ of $\mathrm{H}_{2} \mathrm{O}$. The mixture was placed in a drying oven for $6 \mathrm{~h}$ at $373 \mathrm{~K}$, and subsequently the oven temperature was increased to $433 \mathrm{~K}$ and maintained for $6 \mathrm{~h}$. The sample turned black during the treatment in the oven. The silica sample, containing partially polymerized and carbonized sucrose at the present step, was treated again at 373 and $433 \mathrm{~K}$ using the same drying oven after the addition of $0.8 \mathrm{~g}$ of sucrose, $0.09 \mathrm{~g}$ of $\mathrm{H}_{2} \mathrm{SO}_{4}$, and $5 \mathrm{~g}$ of $\mathrm{H}_{2} \mathrm{O}$. The carbonization was completed by pyrolysis with heating to typically $1173 \mathrm{~K}$ under nitrogen. The silica/carbon composite was immersed in $10 \mathrm{wt} . \%$ hydrofluoric acid solution for one night to remove the silica and get the desired OMC, and the resulting mesoporous carbon was labeled as PE-CMK-3 and CMK-3.

2.3. Characterizations. Powder X-ray diffraction patterns were recorded on a Rigaku D/Max-2500/pc powder diffraction system using $\mathrm{Cu} \mathrm{KD}$ radiation $(40 \mathrm{kV}$ and $250 \mathrm{~mA}$ ) over the range $0.5^{\circ} \leq 2 \theta \leq 5^{\circ}$ (low angle). The unit-cell parameters were calculated from the formula

$$
a_{0}=\frac{2 d_{(100)}}{\sqrt{3}} .
$$

Nitrogen adsorption isotherms were determined at $77 \mathrm{~K}$ with a Micromeritics ASAP 2020 Gas Adsorption Analyzer. The samples were outgassed at $473 \mathrm{~K}$ for $5 \mathrm{~h}$ at vacuum condition before adsorption measurement. Surface area and total pore volume were determined by using the Brunauer-Emmett-Teller (BET) equation and the BarrettJoyner-Halenda (BJH) method, respectively. The pore size distribution was calculated from the analysis of the adsorption branch of the nitrogen isotherm using the BJH method.

\section{Results and Discussion}

The small-angle XRD patterns of the samples can be seen in Figure 1, and it shows the diffraction of the 2D hexagonal space group (p6 mm) and the first intense (100) signal at $2 \theta=$ $0.623 \sim 1.059^{\circ}$. The XRD patterns exhibit well-resolved peaks corresponding to the 100,110 , and 200 planes, indicating the long-range ordering of the SBA-15 (Figure 1(a)), and it is similar to the previous report results. The XRD patterns for other samples show a well-resolved peak at (100), but (110) and (200) peaks are not well separated as SBA-15 silica, indicating its less ordered mesoporous structures than those of SBA-15. 
TABle 1: The samples texture properties.

\begin{tabular}{lccccc}
\hline Samples & $\begin{array}{c}\text { Lattice parameter } \\
a_{0}(\mathrm{~nm})\end{array}$ & $\begin{array}{c}\text { BET area } \\
\left(\mathrm{m}^{2} / \mathrm{g}\right)\end{array}$ & $\begin{array}{c}\text { Mesopore volume } \\
\left(\mathrm{cm}^{3} / \mathrm{g}\right)\end{array}$ & $\begin{array}{c}\text { Micropore volume } \\
\left(\mathrm{cm}^{3} / \mathrm{g}\right)\end{array}$ & $\begin{array}{c}\text { Pore size } \\
(\mathrm{nm})\end{array}$ \\
\hline SBA-15 & 12.8 & 938.54 & 1.29 & 0.13 & 6.64 \\
PE-SBA-15 & 16.4 & 669.87 & 1.43 & 0.07 & 0.07 \\
CMK-3 & 9.6 & 1152.32 & 1.12 & 0.41 \\
PE-CMK-3 & 16.2 & 1213.47 & 1.56 & 0.07 \\
\hline
\end{tabular}

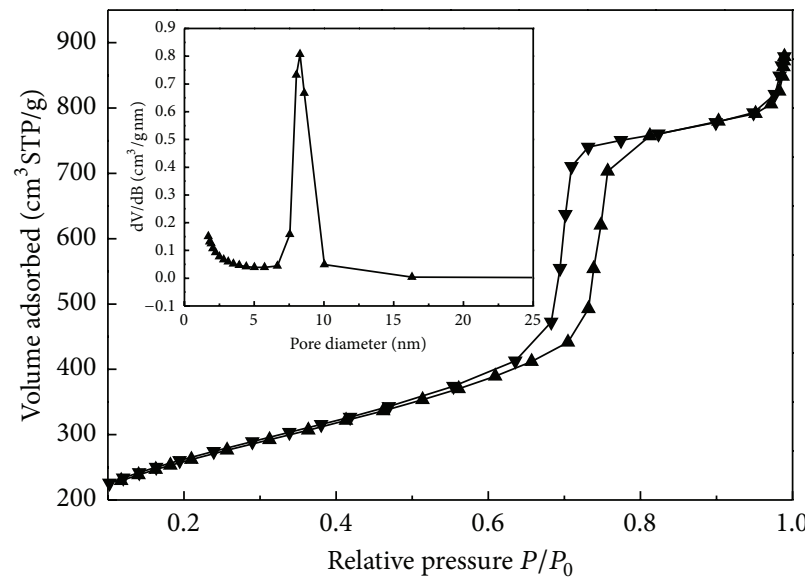

(a)

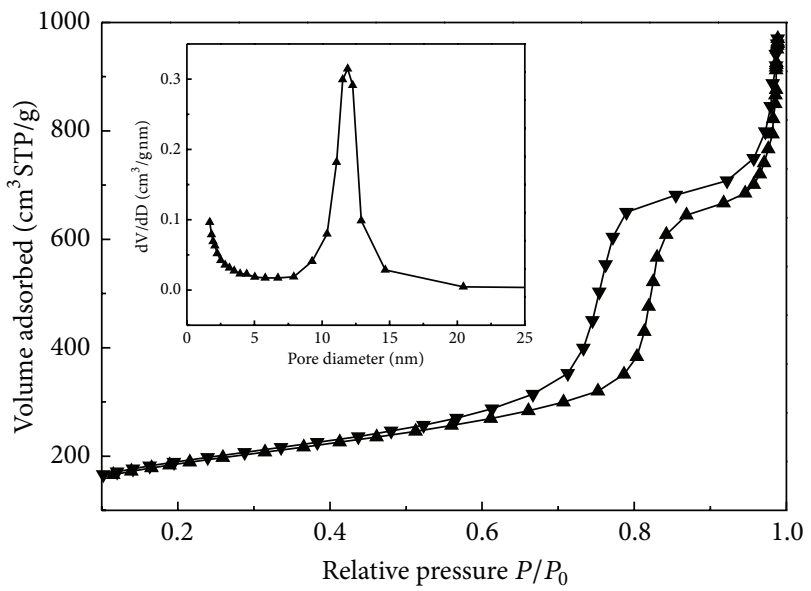

(c)

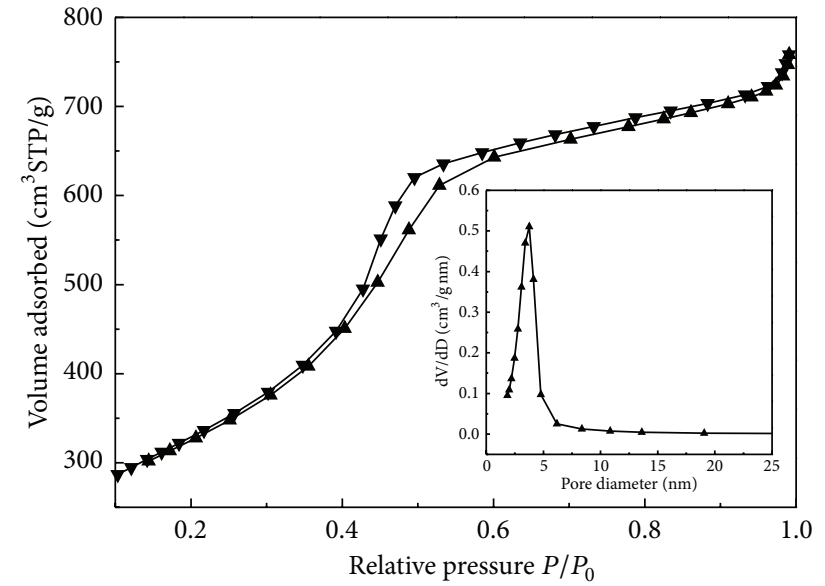

(b)

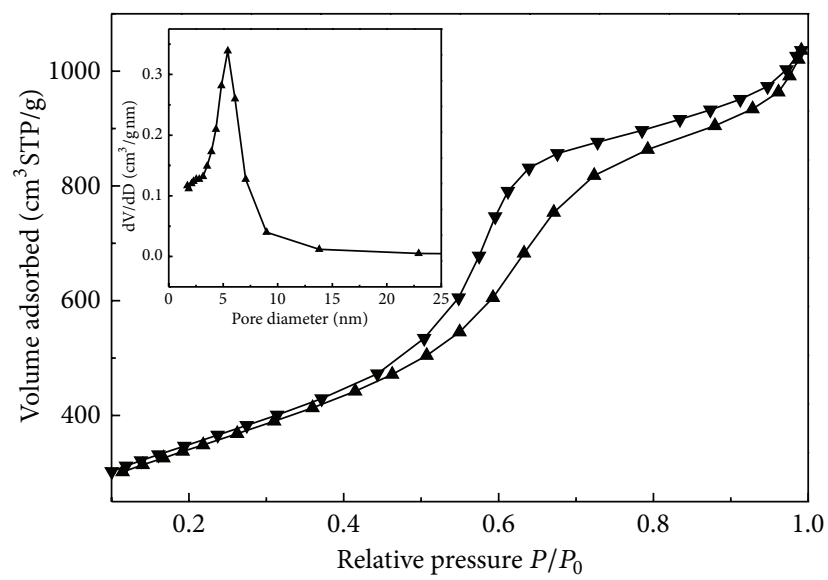

(d)

FIgURE 2: $\mathrm{N}_{2}$ adsorption-desorption isotherms and pore size distribution of (a) SBA-15, (b) CMK-3, (c) PE-SBA-15, and (d) PE-CMK-3.

Figure 2 shows nitrogen adsorption-desorption isotherms and pore size distribution of the resulting mesoporous carbon and its silica template, respectively. Both samples give a type IV isotherm characteristic of a mesoporous material and H1-type hysteresis loops, indicating highly uniform mesopores with narrow pore size distributions. Remarkably, the position of the sharp step in the isotherm gradually shifts to higher relative pressures as the pore size increases. The pore size, lattice parameter, and the total pore volume of SBA-15 and CKM-3 samples increase with the hexane adding (Table 1), and the pore size of the silica SBA-15 increases significantly, while the increase of the OMCs is not so obvious. This may mainly be attributed to the framework shrinkage and inadequate casting process [15]. The BET surface area and pore volume of PE-CMK-3 obviously increase by using pore-expanded SBA-15 as template, indicating that choosing large pore size materials as template is good for preparation of high performance of OMCs.

\section{Conclusions}

The use of low-temperature initial synthesis conditions and hexane as a micelle expander allows one to synthesize highly ordered pore-expanded SBA-15 silica. We successfully synthesized pore-expanded OMCs with 2D hexagonal 
mesostructure by a simple nanocasting process. Pore size controlling technology is an effective method for mesoporous molecular sieve to be the advanced material. The pore size of OMC mainly depends on the template structure, and choosing large pore size materials as template is a simple and effective method to obtain pore-expanded OMCs.

\section{Conflict of Interests}

The authors declare that there is no conflict of interests regarding the publication of this paper.

\section{Acknowledgment}

The authors thank China-Japan International Cooperation Project for supporting this work (2013DFG50150).

\section{References}

[1] R. Ryoo, S. H. Joo, and S. Jun, "Synthesis of highly ordered carbon molecular sieves via template-mediated structural transformation," The Journal of Physical Chemistry B, vol. 103, no. 37, pp. 7743-7746, 1999.

[2] K. Zhu, J. Sun, H. Zhang, J. Liu, and Y. Wang, "Carbon as a hard template for nano material catalysts," Journal of Natural Gas Chemistry, vol. 21, no. 3, pp. 215-232, 2012.

[3] C. He and X. Hu, "Functionalized ordered mesoporous carbon for the adsorption of reactive dyes," Adsorption, vol. 18, no. 5-6, pp. 337-348, 2012.

[4] K. T. Roro, N. Tile, B. Mwakikunga, B. Yalisi, and A. Forbes, "Solar absorption and thermal emission properties of multiwall carbon nanotube/nickel oxide nanocomposite thin films synthesized by sol-gel process," Materials Science and Engineering $B$, vol. 177, no. 8, pp. 581-587, 2012.

[5] Y. Wang, B. Li, C. Zhang et al., "Simple synthesis of metallic $\mathrm{Sn}$ nanocrystals embedded in graphitic ordered mesoporous carbon walls as superior anode materials for lithium ion batteries," Journal of Power Sources, vol. 219, pp. 89-93, 2012.

[6] J. Li, W.-L. Dai, and K. Fan, "Formation of ordered mesoporous $\mathrm{MgO}$ with tunable pore diameter and its application as excellent alkaline catalyst in Baeyer-Villiger oxidation," The Journal of Physical Chemistry C, vol. 112, no. 45, pp. 17657-17663, 2008.

[7] S. Jun, S. H. J. Sang Hoon Joo, R. Ryoo et al., "Synthesis of new, nanoporous carbon with hexagonally ordered mesostructure," Journal of the American Chemical Society, vol. 122, no. 43, pp. 10712-10713, 2000.

[8] M. Enterría, F. Suárez-García, A. Martínez-Alonso, and J. M. D. Tascón, "Synthesis of ordered micro-mesoporous carbons by activation of SBA-15 carbon replicas," Microporous and Mesoporous Materials, vol. 151, pp. 390-396, 2012.

[9] I. Muylaert, A. Verberckmoes, J. de Decker, and P. van der Voort, "Ordered mesoporous phenolic resins: highly versatile and ultra stable support materials," Advances in Colloid and Interface Science, vol. 175, pp. 39-51, 2012.

[10] H. I. Lee, J. H. Kim, D. J. You et al., "Rational synthesis pathway for ordered mesoporous carbon with controllable 30- to 100angstrom pores," Advanced Materials, vol. 20, no. 4, pp. 757-762, 2008.

[11] Y. Li, J. Zhong, X.-Z. Yang, G.-J. Lan, H.-D. Tang, and H.-Z. Liu, "Simple synthesis of semi-graphitized ordered mesoporous carbons with tunable pore sizes," New Carbon Materials, vol. 26, no. 2, pp. 123-129, 2011.

[12] M. Kruk, "Access to ultralarge-pore ordered mesoporous materials through selection of surfactant/swelling-agent micellar templates," Accounts of Chemical Research, vol. 45, no. 10, pp. 1678-1687, 2012.

[13] L. Cao, T. Man, and M. Kruk, "Synthesis of ultra-large-pore SBA-15 silica with two-dimensional hexagonal structure using triisopropylbenzene as micelle expander," Chemistry of Materials, vol. 21, no. 6, pp. 1144-1153, 2009.

[14] J. Sun, H. Zhang, D. Ma et al., "Alkanes-assisted low temperature formation of highly ordered SBA-15 with large cylindrical mesopores," Chemical Communications, no. 42, pp. 5343-5345, 2005.

[15] B. You, Z. D. Zhang, L. L. Zhang, J. Yang, X. L. Zhu, and Q. D. Su, "A new restriction effect of aging time on the shrinkage of ordered mesoporous carbon during carbonization," RSC Advances, vol. 2, no. 12, pp. 5071-5074, 2012. 

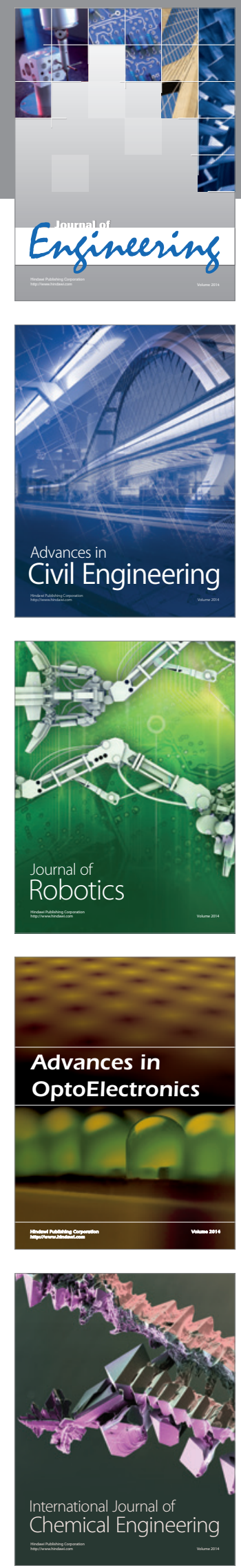

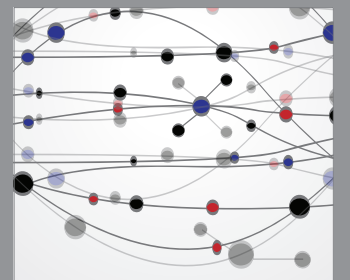

The Scientific World Journal
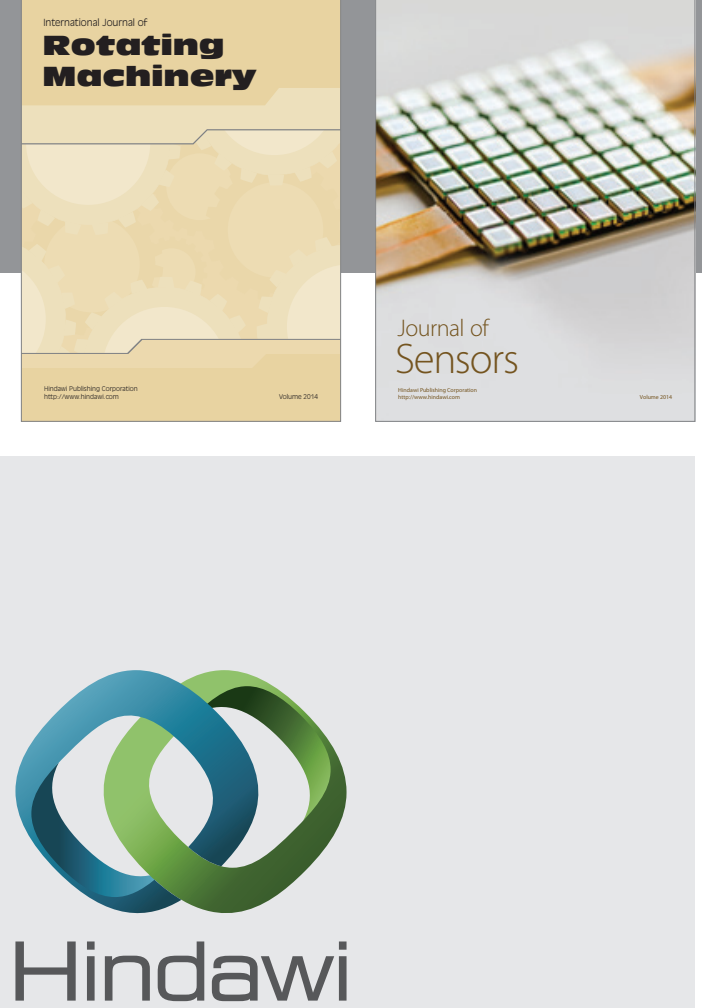

Submit your manuscripts at http://www.hindawi.com
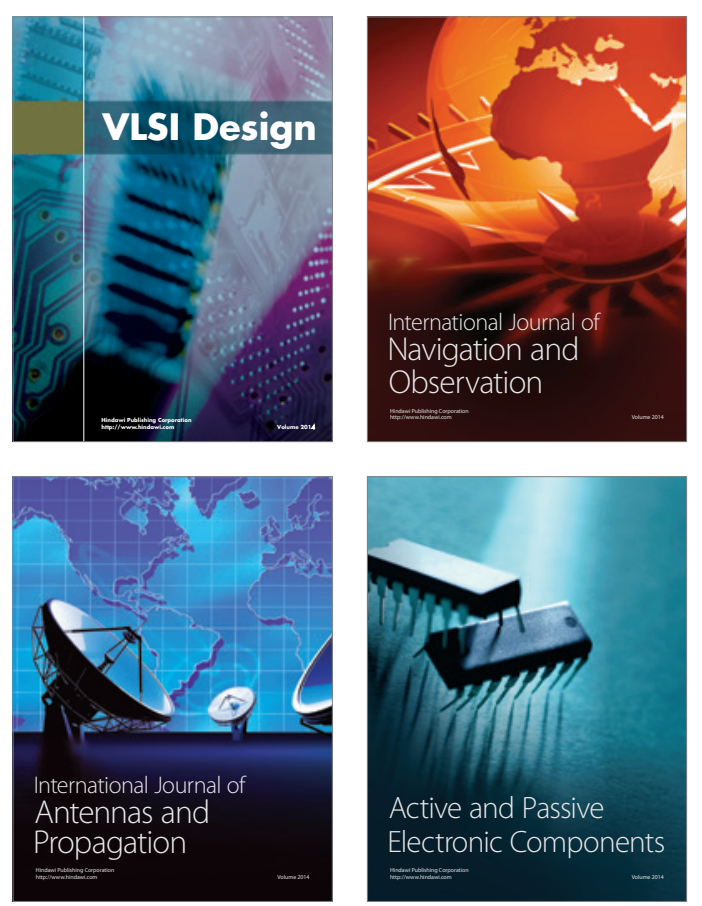
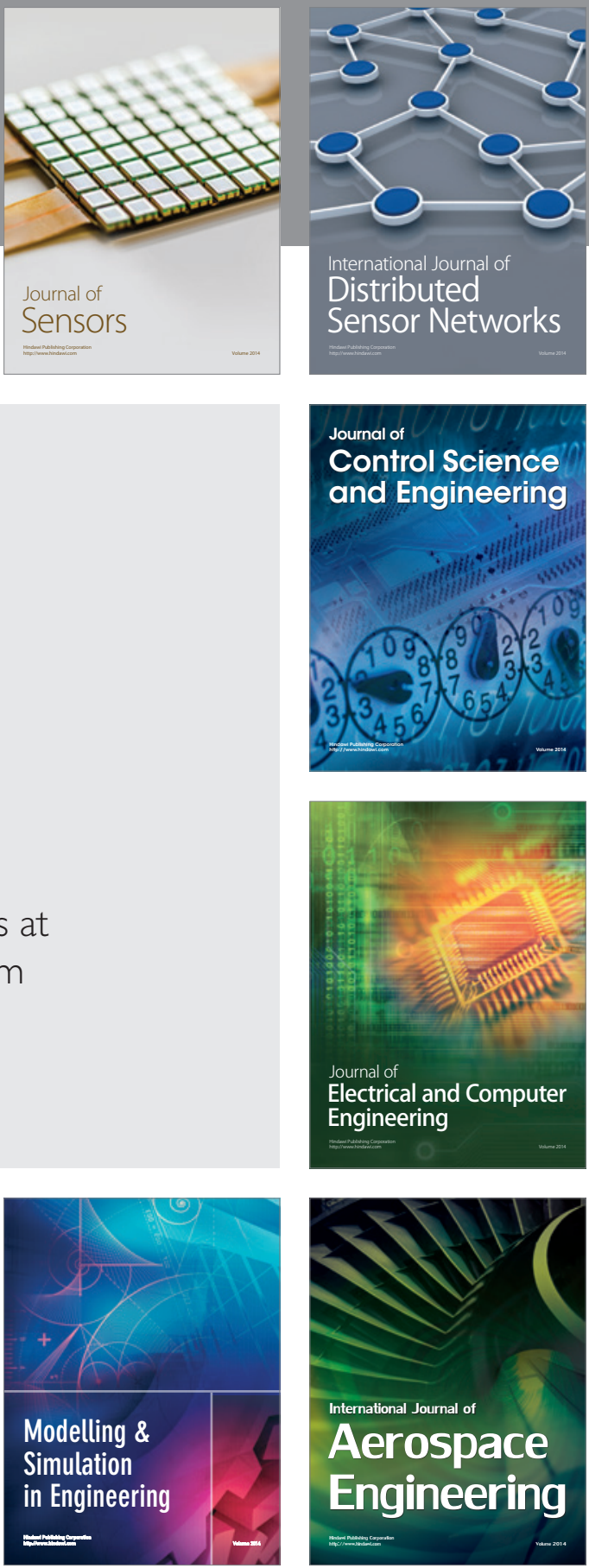

Journal of

Control Science

and Engineering
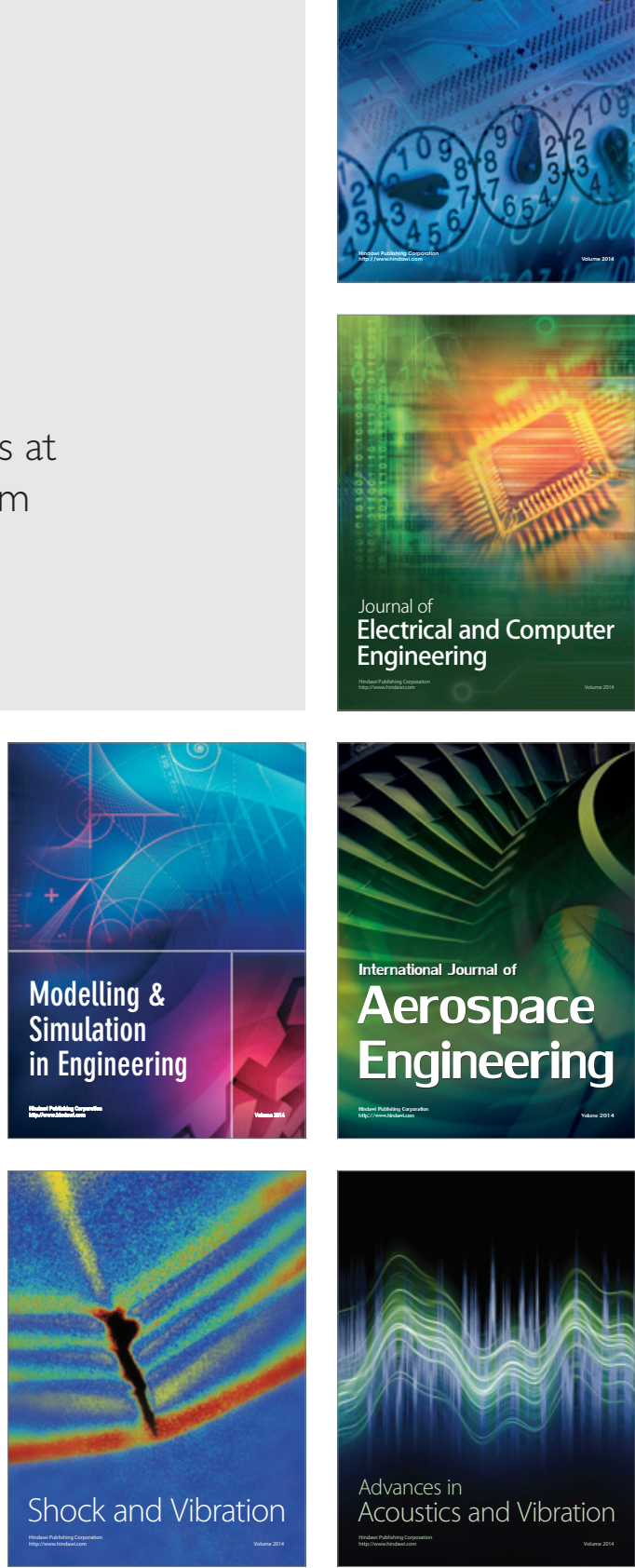